\title{
Ku70 suppresses alternative end-joining in G1-arrested progenitor B cells
}

Zhuoyi Liang ${ }^{1,3}$, Vipul Kumar ${ }^{1,3}$, Marie Le Bouteiller ${ }^{2,3}$, Jeffrey Zurita ${ }^{1}$, Josefin Kenrick², Sherry G. Lin ${ }^{1}$, Jiangman Lou' ${ }^{1}$, Jianqiao $\mathrm{Hu}^{1}$, Adam Yongxin $\mathrm{Ye}^{1}$, Cristian Boboila ${ }^{1}$, Frederick W. Alt ${ }^{1, *}$, and Richard L. Frock $^{1,2 *}$

${ }^{1}$ Howard Hughes Medical Institute, Program in Cellular and Molecular Medicine, Boston Children's Hospital, Department of Genetics, and Department of Pediatrics, Harvard Medical School, Boston, MA 02115, USA.

${ }^{2}$ Stanford University School of Medicine, Division of Radiation and Cancer Biology, Department of Radiation Oncology, Stanford, CA 94305, USA.

${ }^{3}$ Equal Contribution

${ }^{*}$ Frederick W. Alt and Richard L. Frock

Email: alt@enders.tch.harvard.edu, frock@stanford.edu

Author Contributions: ZL, VK, RLF, FWA designed the study. ZL, VK, RLF, SGL performed experiments. JZ, VK, MLB, RLF developed HTGTS-Rep-Rejoin. MLB, RLF developed HTGTS-JoinT-seq. ZL, VK, MLB, JZ, JK, JH, AYY, FWA and RLF analyzed HTGTS data. JL, ZL analyzed GRO-seq data. CB generated a critical cell line. FWA, supervised research conducted at BCH/HMS, RLF supervised research conducted at Stanford University. ZL, VK, MLB, RLF, and FWA wrote the manuscript. Other authors helped polish the manuscript.

Competing Interest Statement: None.

Keywords (3-5): End-Joining, DSB Repair, Cas9, G1-phase, V(D)J Recombination. 


\section{Abstract}

Classical nonhomologous end-joining (C-NHEJ) repairs DNA double-stranded breaks (DSBs) throughout interphase but predominates in G1-phase when homologous recombination is unavailable. Complexes containing the Ku70/80 ("Ku") and XRCC4/Ligase IV (Lig4) core CNHEJ factors are required, respectively, for sensing and joining DSBs. While XRCC4/Ligase IV are absolutely required for joining RAG1/2-endonucease ("RAG")-initiated DSBs during V(D)J recombination in G1-phase progenitor lymphocytes, cycling cells deficient for XRCC4/Ligase IV also can join chromosomal DSBs by alternative end-joining (A-EJ) pathways. Restriction of $\mathrm{V}(\mathrm{D}) \mathrm{J}$ recombination by $\mathrm{XRCC}$ /Ligase IV-mediated joining has been attributed to RAG shepherding $V(D) J$ DSBs exclusively into the C-NHEJ pathway. Here, we report that A-EJ of DSB ends generated by RAG1/2, Cas9:gRNA and Zinc finger endonucleases in Lig4-deficient G1-arrested progenitor B cell lines is suppressed by $\mathrm{Ku}$. Thus, while diverse DSBs remain largely as free broken ends in Lig4-deficient G1-arrested progenitor B cells, deletion of Ku70 increases DSB rejoining and translocation levels to those observed in Ku70-deficient counterparts. Correspondingly, while RAG-initiated V(D)J DSB joining is abrogated in Lig4deficient G1-arrested progenitor B cell lines, joining of RAG-generated DSBs in Ku70-deficient and Ku70/Lig4 double-deficient lines occurs through a translocation-like A-EJ mechanism. Thus, in G1-arrested, Lig4-deficient progenitor B cells are functionally end-joining suppressed due to Ku-dependent blockage of A-EJ, potentially, in association with G1-phase down-regulation of Ligase1. Finally, we suggest that differential impacts of Ku-deficiency versus Lig4-deficiency on $\mathrm{V}(\mathrm{D}) \mathrm{J}$ recombination, neuronal apoptosis, and embryonic development results from Kumediated inhibition of A-EJ in the G1 cell cycle phase in Lig4-defcient developing lymphocyte and neuronal cells. 


\section{Significance Statement}

Alternative end-joining (A-EJ) is implicated in oncogenic translocations and mediating DNA double-strand break (DSB) repair in cycling cells when classical nonhomologous endjoining (C-NHEJ) factors of the C-NHEJ Ligase complex are absent. However, V(D)J recombination-associated DSBs that occur in G1 cell cycle-phase progenitor lymphocytes are joined exclusively by the C-NHEJ pathway. Until now, however, the overall mechanisms that join general DSBs in G1-phase progenitor B cells had not been fully elucidated. Here, we report that $\mathrm{Ku}$, a core C-NHEJ double-strand break recognition complex, directs repair of a variety of different targeted DSBs towards C-NHEJ and suppresses A-EJ in G1-phase cells. We suggest this Ku activity explains how Ku-deficiency can rescue the neuronal development and embryonic lethality phenotype of Ligase 4-deficient mice. 


\section{Introduction}

DNA double-strand breaks (DSBs) arise from sources both intrinsic and extrinsic to the cell, and improper DSB repair can lead to genomic instability and oncogenic translocations. To resolve DSBs, mammalian cells largely use two major classes of repair pathways: classical nonhomologous end-joining (C-NHEJ), which is active throughout interphase, and homology directed repair (HDR), which is only active in S/G2 cell cycle phases (Scully et al., 2019; Chang et al., 2017). In the absence of C-NHEJ, cycling cells have been found to also join DSB by an alternative end-joining pathway or pathways (Chang et al., 2017)

Programmed, cell-intrinsic DSBs are generated during $\mathrm{V}(\mathrm{D}) \mathrm{J}$ recombination in developing $B$ and $T$ lymphocytes. $V(D) J$ recombination assembles $V, D$, and $\mathrm{J}$ gene segments into variable region exons within antigen receptor loci of lymphocyte progenitors during the G1 cell cycle phase (Teng and Schatz, 2015). The RAG1/2 (RAG) endonuclease is recruited to a recombination center in antigen receptor loci (Teng and Schatz, 2015; Lin et al., 2018), where it binds recombination signal sequence (RSS) located adjacent to $\mathrm{V}, \mathrm{D}$, and $\mathrm{J}$ gene segments in one of its two active sites (Kim et al., 2015; Ru et al., 2015). Then, the single RSS-bound RAG linearly scans long-range distances of adjacent chromatin in the locus, presented by cohesinmediated loop extrusion, for compatible RSSs with which to mediate cleavage (Hu et al., 2015; Zhao et al, 2016; Jain et al., 2018; Lin et al., 2018; Zhang et al., 2019b, Ba et al., 2020; Hill et al., 2020; Dai et al., 2021). Once two RSSs are appropriately paired, RAG cleaves between the two sets of RSSs and their coding ends to form RSS and coding-end (CE) DSB ends that are held in a post-cleavage synaptic complex (Schatz and Swanson 2011). Joining of cleaved RSS ends to each other and coding ends each other, respectively, is subsequently carried out exclusively by C-NHEJ (Alt et al., 2013; Kumar and Alt 2016), potentially due to RAG shepherding the broken ends specifically into the C-NHEJ pathway (Lee et al., 2004; Corneo et al., 2007). V(D)J recombination end-specific joining is unlike most chromosomal translocations or deletions (involving, for example, Cas9:gRNA or other types of DSBs) in which a given DSBend can join to either DSB end of the other DSB (Chiarle et al., 2011; Frock et al., 2015).

C-NHEJ contains the "core" factors Ku70/Ku80 (Ku), which form the DSB recognition complex, as well as XRCC4/Ligase IV (Lig4), which forms the DSB ligation complex. Core C- 
NHEJ factors are necessary for joining CEs and RSS ends during V(D)J recombination in G1phase developing lymphocyte progenitors; accordingly, mice deficient for core C-NHEJ factors exhibit a severe combined immune deficiency (SCID) due to defective repair during $V(D) J$ recombination (Alt et al., 2013; Kumar and Alt 2016). However, Ku70-deficient mice can have a "leaky" SCID when compared to a complete SCID in XRCC4/Lig4-deficient mice, consistent with low level of V(D)J recombination-like joining in the absence of Ku (Gu et al., 1997). Deficiency for core C-NHEJ factors also leads to substantial p53-dependent apoptosis of newly generated post-mitotic neurons (Frank et al., 2000; Gao et al., 1998; 2000); however, the impact of Ku deficiency on neuronal apoptosis is not nearly as severe as that of XRCC4 or Ligase4 (Lig4) deficiency (Gu et al., 2000).

As defined in the context of core C-NHEJ deficiency, cycling mammalian cells can also access an alternative end-joining (A-EJ) pathway (or pathways) to relatively robustly join DSB ends generated via translocations or during Immunoglobulin heavy chain $(\mathrm{lgH})$ Class Switch Recombination (CSR) in mature B cells (Zhu et al., 2002; Yan et al., 2007; Boboila et al. 2010b). A-EJ also joins chromosomally I-Scel-generated DSBs in cycling mammalian cell lines (Guirouilh-Barbat et al., 2007; Boboila et al., 2012), fuses dysfunctional telomeres (Sfeir and de Lange et al., 2012), and promotes translocations to replication stress-enhanced recurrent DSB clusters in neural stem and progenitor cells (Wei et al., 2016). Implicated A-EJ factors include: Parp1, XRCC1/Ligase III (Audebert et al., 2004; Sfeir and de Lange, 2012), Pol $\theta$ (MateosGomez et al., 2015; Ceccaldi et al., 2015), and RAD52 (Zan et al., 2017). Recent studies have also implicated Pol $\theta$ as specifically involved in A-EJ in the S/G2 phase (Yu et al., 2020). Cumulatively, studies of A-EJ have not fully addressed all contexts through which cells commit to A-EJ versus C-NHEJ (Mansour et al, 2013; Truong et al., 2013; Soni et al., 2014; Shamanna et al., 2016; Bakr et al., 2016; Kang and Yan 2018; Yu et al., 2020). In the context of V(D)J recombination, the post-synaptic RAG complex itself has been implicated in shepherding V(D)J RSS and coding end DSBs into the C-NHEJ versus A-EJ pathways in G1-phase progenitor B cell lines (Lee et al., 2004; Corneo et al., 2007; Kumar and Alt 2016). However, whether RAG generated DSBs can translocate to more general DSBs or whether repair of general DSBs in 
G1-arrested progenitor B cells can employ A-EJ have remained to be determined (Yu et al, 2020).

XRCC4 or Lig4-deficient mice succumb to embryonic lethality, which along with their severe neuronal apoptosis is rescued by p53-deficiency, with rescue of neuronal development, and embryonic development potentially occurring by rescue of newly generated Lig4 and XRCC4-deficient neurons from p53-dependent apoptosis in the presence of large numbers of unrepaired DSBs (Frank et al., 2000; Gao et al., 2000). In contrast, Ku-deficient mice do not have an embryonic lethal phenotype and, correspondingly, exhibit a much milder neuronal apoptosis phenotype (Nussenzweig et al.,1996; Gu et al., 1997; Gu et al., 2000). Notably, Kudeficiency rescues the embryonic lethality of Lig4-deficiency mice and has related effects in cell lines (Adachi et al., 2001; Karanjawala et al., 2002). In this context, Ku binding to unrepaired breaks in the context of Lig4- or XRCC4-deficient newly generated neurons has been speculated to suppress their ability to repair persistent DSBs by A-EJ and, thereby, promote their survival (Haber, 2008; Alt et al. 2013). As DSBs can be substantially joined by A-EJ in cycling Lig4- or XRCC4-deficient cells (Yan et al., 2007; Guirouilh-Barbat et al., 2007), such Kudependent down-regulation of A-EJ could in theory have more impact in non-cycling cells such as neurons and G1-phase progenitor B cells.

To ascertain whether additional mechanisms that might restrict joining of RAG-initiated DSBs and determine whether joining of other types of DSBs is also restricted in the G1 cell cycle phase, we mapped RAG-, Cas9:gRNA- and Zinc finger nuclease-generated DSB repair fates in $\mathrm{G} 1$-arrested $v$-Abl-transformed progenitor $\mathrm{B}$ cell lines through a version of our linear amplification-mediated, high-throughput, genome-wide translocation sequencing (LAM-HTGTS) (Hu et al., 2016) modified to map bait DSB rejoining at single nucleotide resolution.

\section{Results}

\section{Repair of Cas9:gRNA DSBs in G1.}

We derived two independent clonal wildtype v-Abl-transformed progenitor $B$ cell lines (Abl lines) designated "WT A" and "WT B" Abl lines, respectively (see Methods). We derived clonal "Ku70-/-A1" and "Lig4 ${ }^{-/} \mathrm{A} 1$ " Abl lines from WT A and "Ku70-/-B1" and "Lig4 ${ }^{-/-B 1 " ~ f r o m ~ W T ~ B ~}$ Abl lines, respectively, (see Methods). We also obtained two independent Lig4-deficient (Lig4 ${ }^{-/}$) 
Abl lines (Bredemeyer et al., 2006; Lee et al., 2013), which we termed "Lig4 ${ }^{-/}$C" and "Lig4 ${ }^{-/} \mathrm{D}$ " lines (Fig. S1A-G). As reported in earlier studies (Gu et al., 1997) loss of Ku70 decreases Ku80 protein to virtually undetectable levels, resulting in a complete loss of the Ku complex (Fig. S1A, S1E). Treatment with STI-571 for all Abl lines described causes G1-arrest, induction of RAG expression, and $\mathrm{V}(\mathrm{D}) \mathrm{J}$ recombination at endogenous antigen receptor loci including the $\mathrm{lg}$ kappa ( $\lg \kappa)$ locus with Abl lines surviving under G1-arrest throughout experiments due to the $\mathrm{E} \mu-\mathrm{Bcl} 2$ transgene present in the original $\mathrm{A}$ and $\mathrm{B}$ wildtype lines (Bredemeyer et al., 2006).

We introduced a Cas9:guide RNA (gRNA) bait DSB targeting the first intron of $c-M y c$ (Hu et al., 2015) in G1-arrested Abl cells and employed HTGTS-JoinT-seq (HTGTS-based reJoining and Translocation sequencing)(Supplement Methods) to measure genome-wide "prey" translocations from the 5' "bait" DSB broken end and to measure imperfect rejoining of the $5^{\prime}$ bait DSB to its corresponding 3' broken end, both at single nucleotide resolution. The use of a modified pipeline was necessary given that the original LAM-HTGTS translocation pipeline (Hu et al., 2016) detects only very few imperfectly rejoined bait DSB junctions in G1-arrested WT Abl cells due to limited resection in the G1 phase (Fig. S2A-C). We performed three independent replicates of experiments for each line assayed, for a combined total of approximately 100,000 junctions from each WT Abl line (Fig. 1A, B and Table S1). Genomewide plots from the Cas9:c-Myc bait for each G1-arrested, WT A and B Abl cells displayed three distinct junction groups: 1) bait DSB ends rejoined to each other (i.e. the bait break-site), 2) recurrent translocations to RAG-initiated DSBs in antigen receptor loci and 3) low-level, widespread translocations (Alt et al., 2013; Frock et al., 2015) (Fig. 1A, B). As predicted, the majority of recovered junctions from G1-arrested WT A and WT B Abl cells involved rejoining of the bait DSB ends (approximately $97 \%$ of total junctions) with a limited mean resection distance (<1bp) (Fig. 1A-E and Tables S1, S2). In this regard, rejoined junctions predominantly harbored small insertions (approximately 70-90\%), consistent with known polymerases that work with CNHEJ (Pryor et al., 2015; Gouge et al., 2015; Stinson et al., 2020), with the remaining junctions being either direct joins (5-20\%) or employing short microhomologies (MHs)(1-10\%) (Fig. 1F, G). Given the very high proportion of bait DSB rejoins relative to translocations, we have 
focused here on rejoining outcomes of the bait DSB ends except for internal RAG-generated DSBs Igא locus joining which occurs more frequently.

$\mathrm{Lig}^{-/-} \mathrm{A} 1$ and Lig4 ${ }^{-/} \mathrm{B} 1 \mathrm{Abl}$ cells were G1-arrested and then expressed with Cas9:c-Myc to measure repair in the absence of C-NHEJ. Strikingly, we recovered very few junctions with the total being $100-1,000$ fold fewer than the number recovered from WT clones and approaching background levels (Fig. 1A-E and Table S1). Southern blotting analyses of the Cas9:c-Myc bait break-site revealed little change in the germline band, consistent with dominant rejoining with limited resection; however, a substantial fraction of the $c-M y c$ alleles in G1arrested Lig4 $^{-/}$Abl cells were present as un-joined DSB ends (Fig. 1C and Fig. S3A-C), demonstrating substantial bait site cutting but little rejoining in the latter. Retroviral complementation of Lig4 ${ }^{--} \mathrm{A} 1 \mathrm{Abl}$ cells with Lig4 (Fig. S1B) restored joining patterns, junction structures, and median resection distance similar to those observed in WT (Fig. 2A-C and Tables S1, S2) and, correspondingly, with a decreased level of Cas9:c-Myc bait broken ends as detected by Southern blotting (Fig. S3D.) Finally, cycling WT A and Lig4 ${ }^{-{ }^{-}} \mathrm{A} 1 \mathrm{Abl}$ cells robustly rejoined the Cas9:C-Myc bait DSB ends. The majority of junctions from cycling WT A harbored short insertions over a mean resection distance of approximately $70 \mathrm{bp}$, whereas cycling Lig ${ }^{-/-}$ A1 were nearly all short MHs over a mean resection distance of approximately 300bp (Fig. S4A, B, Tables S1, S2), and no discernable change was observed in the Southern blot band harboring Cas9:C-Myc bait DSB (Figs. S4C). We conclude that the inability to rejoin in G1arrested Lig4 ${ }^{-/} \mathrm{Abl}$ cells is specific to both the absence of Lig4 and the G1 cell cycle phase.

Ku-deficiency has differential impacts on organismal development than XRCC4/Lig4deficiency (Gu et al., 1997; Frank et al., 1998). Thus, we evaluated A-EJ of Cas9:c-Myc DSBs in G1-arrested Ku70-/-A1 and B1 Abl cells. Contrary to the near complete absence of A-EJ in G1arrested Lig4 ${ }^{-/}$Abl cells, Ku-deficient A-EJ was robust with recovered junctions at similar to slightly lower levels than that of WT Abl cells (Fig. 1A, B and Table S1, S2). Notably, Ku deficiency increased the mean resection distance of bait DSB rejoined junctions (to approximately 45bp) compared to WT Abl cells (Table S2). Despite the robust G1-arrested $\mathrm{Ku}^{-/-}$A-EJ (Fig. 1D, E), Southern blotting analysis displayed substantial unrepaired bait DSB ends (Fig. S3A-C). Ku-deficient rejoined junction structures predominantly consisted of small 
MHs (approximately 66\%), but with a high fraction of direct joins (approximately $30 \%$ )(Fig. 1F, $\mathrm{G).}$

Because Ku deficiency can rescue the embryonic lethality of Lig4 deficiency (Karanjawala et al., 2002), we hypothesized that the presence of Ku in G1-arrested Lig4 ${ }^{-/-} \mathrm{Abl}$ cells may block access of DSBs to A-EJ (Alt et al., 2013). To test this, we deleted Ku70 from $\mathrm{Lig}^{-/-} \mathrm{A} 1$ and $\mathrm{C}$ Abl cell lines (generating Lig4 ${ }^{-/-} \mathrm{Ku} 70^{-/-} \mathrm{A} 1-1$ and $\mathrm{C} 1$ lines)(Fig. S1A, E) and assayed rejoining outcomes. Indeed, loss of Ku70 in Lig4 ${ }^{-/-}$Abl cell lines fully restored G1phase joining patterns (e.g. increased resection, rejoining of bait ends, and direct junction utilization) to those observed in G1-arrested Ku70-1-A1 and B1 Abl cells (Fig. 2A-C and Figs. S5A, B, S6A-C, Tables S1, S2). Furthermore, complementation of Ku70 in Lig4 ${ }^{-1-K u 70^{-/}} \mathrm{A} 1-1$ and C1 Abl cell lines (Fig. S1E), suppressed repair levels approximately 100-fold, to low levels that approached those of G1-arrested Lig4 ${ }^{-/-}$Abl cell lines (Fig. 2A-C and Figs. S5A, B, S6A-C, Table S1), demonstrating that rejoining suppression was indeed Ku70-specific. We conclude that in G1-arrested Lig4 ${ }^{-/-}$Abl cells, A-EJ for Cas9 DSBs is suppressed by the Ku C-NHEJ DSB recognition complex.

\section{Repair of 5' overhangs in G1.}

To determine whether DSB repair differences between C-NHEJ and A-EJ proficient backgrounds extend beyond repair of blunt DSB ends, we employed Lig4 ${ }^{-1-} \mathrm{D}$ Abl cells, which harbor a doxycycline inducible zinc finger nuclease (ZFN) that targets the TCR $\beta$ locus enhancer on chromosome 6 (Eb-ZFN)(Lee et al., 2013). Upon doxycycline treatment, the ZFNs generate DSBs containing 4bp long 5' overhang ends (Smith et al., 2000). We then generated a WT equivalent control by retroviral expression of Lig4 in these Lig4 ${ }^{-/-} \mathrm{D}$ Abl cells (Figs. S1F). G1arrested Lig4 ${ }^{--} \mathrm{D}$ Abl cells displayed approximately 20 -fold fewer total junctions from Eb-ZFNinduced DSBs than their Lig4-complemented G1-arrested counterparts (Fig. 3A, B), and, unlike their Lig4-complemented G1-arrested counterparts, accumulated substantial levels of unrepaired broken ends (Fig. S7A, B). Notably, although at low levels, significant numbers of junctions from Eb-ZFN expressing G1-arrested Lig4 ${ }^{-/-} \mathrm{D}$ Abl cells were recovered (Fig 1A-E, 3A, $\mathrm{B}$ and Table S1). Furthermore, junctions recovered from the G1-arrested Lig4-complemented $\mathrm{Lig}^{-/-} \mathrm{D}$ abl cells again predominantly contained short insertions with a limited mean resection 
distance (5bp) similar to rejoined Cas9:c-Myc bait DSB ends in WT Abl cells (Fig. 3C and Table S1, S2).

To examine the influence of Ku on Eb-ZFN-generated DSBs, we deleted Ku70 from two separate clones of Lig4 ${ }^{-/-} \mathrm{D}$ Abl cells to generate Lig4 ${ }^{-1-} \mathrm{Ku} 70^{-/-} \mathrm{D} 1$ and D2 Abl lines, which led to an approximately 20-30 fold increase in Eb-ZFN junctions recovered in the presence of Eb-ZFN; in this context, rejoined bait DSB junction structures predominantly contained short $\mathrm{MHs}(70 \%)$ but also had substantial numbers that were direct (30\%), consistent with Cas9:c-Myc bait findings (Fig. 3A-C and Figs. S7C, D, S8A-C, Table S1). Correspondingly, ectopic expression of Ku70 in Lig4 ${ }^{-/-K u} 70^{--}$D1 and D2 Abl lines (Fig. S1G), in the presence of Eb-ZFN, decreased junction numbers to levels comparable to Lig4 ${ }^{-/}$D Abl cells (Fig. 3A, B and Figs. S7C, D, S8A-C, Table S1). Collectively, we conclude that the inability to repair DSBs in G1-arrested Lig4 ${ }^{-{ }^{-}} \mathrm{Abl}$ cells, due to Ku suppression of A-EJ, also largely applies to ends with short 5' overhangs.

\section{A-EJ of RAG-initiated DSBs.}

Given that Ku suppresses A-EJ for Cas9 and ZFN DSBs (above) and that Ku70-1- mice can display a leaky SCID phenotype (Gu et al., 1997), we revisited the extent to which A-EJ participates in a V(D)J recombination-like process. Thus, we employed HTGTS-V(D)J-seq to measure the joining of the $J_{\kappa} 1$ CE to other potential bait DSB ends which includes the approximately $130 \mathrm{~V}_{\kappa}$ gene segment CEs and their associated RSS ends (Hu et al., 2015; Zhao et al., 2016; Jain et al., 2018; Zhang et al., 2019b, Ba et al., 2020; Dai et al., 2021). Vк gene segments in Igк are either in deletional (blue bars) or inversional (red bars) recombination orientation relative to $\mathrm{J}_{\kappa}$ gene segments (Fig. 4A-D and SI Appendix Fig. S9A-D). As expected for the Jא1 CE bait, WT A and B Abl libraries generated hundreds of thousands of junctions, displayed as highly orientation-biased joining to individual $\mathrm{V}_{\kappa} C E s$, consistent with the $V(D) J$ recombination mechanism (Fig. 4A, B-and Table S3)(Hu et al., 2015; Zhao et al., 2016; Jain et al., 2018; Lin et al., 2018; Zhang et al., 2019b, Chen et al., 2020; Ba et al., 2020; Dai et al., 2021). Most $V_{\kappa}$ to $J_{\kappa} V(D) J$ recombination-mediated joints were either direct or contained short insertions (Fig. 4E and Fig.S9E), consistent with high level TdT expression in these lines (Fig. S9G), which obviates use of dominant MHs between $V_{\kappa}$ and $J_{\kappa}$ junctional sequences (Komori et al, 1993). We found little to no RAG DSB junctions in Lig4 ${ }^{-/-}$A1, B1, and C Abl cell lines, and, 
correspondingly, these lines accumulated stable $\mathrm{J}_{\kappa}$ broken ends (Fig. 4A-D and Figs. S9A-D, S10A, B, S11A, B, Table S3). Lig4-complementation of Lig4 ${ }^{-/-}$A1 and C Abl lines attenuated levels of $J_{\kappa}$ broken ends and restored normal $V_{\kappa}$ to $J_{\kappa}$ joining with orientation bias, and junction structures characteristic of normal V(D)J recombination (Fig. 4A, B, E and Fig. S9C-F, S10C, S11B, Table S3).

In contrast to $\mathrm{WT} V(\mathrm{D}) \mathrm{J}$ recombination, we found significant levels of joining of the $\mathrm{J}_{\kappa} 1$ bait end to $\mathrm{V}_{\kappa} \mathrm{CES}$ and RSS ends in $\mathrm{Ku}^{-/-} \mathrm{A} 1$ and $\mathrm{B} 1 \mathrm{Abl}$ cells, albeit at levels that were 5-10 fold lower than the levels of bona fide $V_{\kappa}$ to $J_{\kappa}$ junctions in WT $A$ and $B$ Abl lines (Fig. 4A, B and Fig. S9A, B, S10B, S11A, Table S3). Thus, the $\mathrm{J}_{\kappa} 1 \mathrm{CE}$ junctions in the Ku70-/-A1 and B1 Abl cells were not orientation-biased toward $\mathrm{V}_{\kappa} \mathrm{CEs}$ like with $\mathrm{C}-\mathrm{NHEJ}$, but rather, were balanced for both $V_{\kappa} C E s$ and $V_{\kappa} R S S s$ (Fig 4A-D and Fig S9A-D, Table S3); thereby, indicating that they were joined by an A-EJ-mediated repair mechanism as opposed to end-specific joining by bona fide $\mathrm{V}(\mathrm{D}) \mathrm{J}$ recombination. A significant fraction of the $\mathrm{V} \kappa$ to $\mathrm{J}_{\kappa} \mathrm{A}-\mathrm{EJ}$ mediated joins in $\mathrm{Ku}-$ deficient cells (approximately 30\%) were potentially productive in that they fused the $\bigvee_{\kappa}$ into the $J_{\kappa}$ in frame (Fig. $S 9 H$ ) with a major subset of those that maintain $V_{\kappa}$ and $J_{\kappa}$ sequences with little or no deletion/resection similar to those of functional joins in WT cells (Fig. 4B). Finally, deletion of $\mathrm{Ku}$ in Lig4 ${ }^{-1-} \mathrm{A} 1$ and $\mathrm{C}$ Abl cells rescued $\mathrm{V}_{\kappa}$ to $\mathrm{J}_{\kappa}$ junctions to levels comparable to those found in the context of Ku70-deficiency alone (Fig. 4C-F and Fig. S9C-F, S10D, S11C, Table

S3). Such A-EJ mediated joins could be responsible for the leaky "V(D)J" recombination phenotype of $\bigvee_{\kappa}$ to $\mathrm{J}_{\kappa}$ joining in Ku-deficient mice described previously (Gu et al., 1997).

\section{Discussion}

We report that DNA DSBs generated by three different classes of endonucleases: RAG, Cas9:gRNA, and ZFN in G1-arrested Abl cells accumulate as un-joined broken ends in the absence of the Lig4 core C-NHEJ factor. We further define the mechanism as suppression of A-EJ in these $\mathrm{G1}$-arrested cells by $\mathrm{Ku}$. This finding is notable as it greatly contrasts with relatively robust A-EJ of general or CSR-associated DSBs reported previously in the absence of Lig4 or its essential XRCC4 co-factor complex in various cycling contexts (Boboila et al., 2010a; Boboila et al., 2010b; Boboila et al., 2012, Yu et al.,2020). While A-EJ is often considered a single pathway, two pathways of A-EJ have been proposed to be capable of mediating CSR in 
cycling B cells. One pathway, which occurs in Lig4-deficient B cells, uses almost exclusively $\mathrm{MH}-$ mediated joins and potentially represents a variation of C-NHEJ that likely uses Lig1 (Boboila et a., 2010b; Boboila et al., 2012). The second pathway found in the absence of either Ku or Ku plus Lig4, substantially uses direct joins, and represents a true A-EJ pathway, since it occurs in the absence of C-NHEJ recognition and joining components (Boboila et a., 2010b). The A-EJ pathway that operates in Ku-deficient G1-arrested Abl cells, generally matches well with the latter end-joining pathway and, thus, represents a bona fide A-EJ pathway. On the other hand, the C-NHEJ variant pathway that operates in CSR is essentially absent in G1arrested Abl cells, consistent with very low level Lig1 expression in these and other G1-arrested cells (Fig. S12A-F, S13)(Akbari et al., 2009). Notably, however, joining of ZFN-generated DSBs in Lig4-deficient, G1-arrested Abl cells was substantially, but not completely suppressed by Ku, with recovered joins mostly $\mathrm{MH}$-dependent, consistent with mediation by the variant C-NHEJ pathway using Lig3. There are various mechanisms by which ZFN-generated DSBs access this joining pathway at low-level, for example if ZFN-binding partially interferes with Ku-binding, but resolution of the mechanism will require further investigation.

Our findings provide a molecular mechanism that could enforce the shepherding of RAG-initiated DSBs to repair by C-NHEJ, versus A-EJ, during V(D)J recombination (Corneo et al., 2007; Deriano et al., 2011; Gigi et al., 2014; Lescale et al., 2016). Our findings also provide a cellular mechanism as to why Ku deficiency versus XRCC4/Lig4 deficiency differentially impacts developmental processes in vivo. With respect to lymphoid development, we have now mechanistically defined why low-level joining of RAG-initiated DSB joining occurs during V(D)J recombination in Ku70-deficient versus Lig4- or XRCC4-deficient mice (Gu et al., 1997; Gu et al., 2000). In this context, the inefficient translocation-based joining of $V_{\kappa}$ and $J_{\kappa}$ gene segments that escape the RAG post-synaptic complex are fused to make $\mathrm{V}(\mathrm{D}) \mathrm{J}$-like joints of which a significant proportion can serve as functional joins (Hu et al., 2015). In addition, we speculate that our findings may explain the differential impact of Ku-deficiency versus Lig4- or XRCC4deficiency on embryonic development. Thus, our findings support the hypothesis (Haber, 2008; Alt et al., 2013) that absence of Ku allows A-EJ to rejoin a substantial fraction of DSBs in postmitotic neurons and, thereby, does not impact embryonic viability; whereas, the abrogation of 
end-joining, mediated by the Ku complex, would lead to an intolerable DSB burden and embryonic lethality in the context of Lig4- or XRCC4-deficiency. This model also can explain why Ku-deficiency rescues embryonic lethality of XRCC4/Lig4-deficient mice (Karanjawala et al., 2002).

\section{Methods}

Generation of Cell lines and Reagents. "WT A" Abl cell line was generated from a Lig4 ${ }^{\text {flox/flox }} \mathrm{E} \mu-\mathrm{Bcl}$ 2 transgenic mouse as previously described (Boboila et al., 2010a). The "WT B" $\mathrm{Abl}$ cell line was generated from an $\mathrm{E} \mu-\mathrm{Bcl} 2$ transgenic mouse. Lig4 ${ }^{-/-} \mathrm{A} 1$ was generated by $\mathrm{Cre}$ deletion, using adeno-Cre recombinase, from WT A. Ku70-- A1 was generated from WT A and

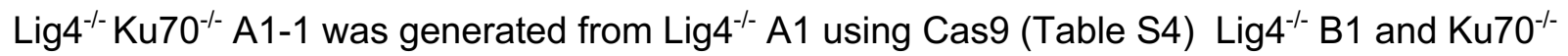
B1 Abl lines were generated from WT B. Lig4 ${ }^{-/-}$C and Lig4 ${ }^{-/-}$D (Eb-ZFN) (Lee et al., 2013) were gifts from Barry Sleckman (University of Alabama at Birmingham); Lig4 ${ }^{-1-} \mathrm{Ku} 70^{-/-} \mathrm{C} 1$ was derived from Lig4 ${ }^{-/-} \mathrm{C}$; Lig4 ${ }^{-1-K u} 70^{-1-} \mathrm{D} 1$ was derived from Lig4 ${ }^{-/-} \mathrm{D}$ (Table S4). All CRISPR/Cas9 generation and screening of knock-out cell lines was performed as previously described (Kumar

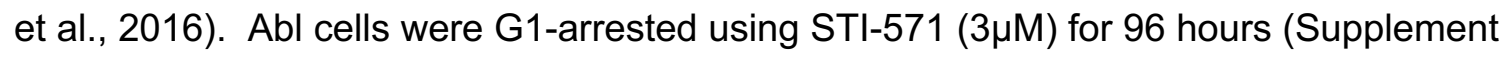
Methods).

NGS sample preparation and HTGTS-JoinT-seq. Designer nuclease bait experiments employed HTGTS-JoinT-seq. Junction-enriched libraries were generated as previously described for LAM-HTGTS (Hu et al., 2016) but with the removal of the bait DSB rejoining blocking step. Input genomic DNA for each junction library sample/replication was $12 \mu \mathrm{g}$ and all sequences were aligned to the mm10 genome build. Libraries were sequenced by Illumina Miseq (250PE) or Nextseq (150PE) and primers specific to each are indicated (Table S4). Pooled raw sequences were demultiplexed and adapter trimmed using TranslocPreprocess $(\mathrm{Hu}$ et al., 2016). Libraries were then normalized to the same number of raw reads within each experiment. Translocations were identified using TranslocWrapper (Hu et a., 2016) with additional modifications, followed by mapping rejoined bait ends using the $\mathrm{R}$ module, JoinT (Supplement Methods). See SI Appendix for description of HTGTS-Rep-Rejoin. 
HTGTS-V(D)J-seq and Hotspot analysis. HTGTS-V(D)J-seq (Ba et al., 2020) was performed for the $\mathrm{J}_{\kappa} 1$ coding end bait as similarly described (Hu et al., 2015; Zhao et al., 2016) using the mm10 genome build and only junctions within 200bp of bona fide Vк RSSs, with or without 150bp of bona fide $\mathrm{J}_{\kappa}$ RSSs were described. For all NGS experiments, MACS2-based algorithm was used with a false detection rate (FDR) cutoff of $10^{\wedge}-10$ as described (Frock et al., 2015). Hotspots were called if enriched sites were significant in all replicate libraries.

Southern analysis. Southern blots were performed with $20 \mu \mathrm{g}$ of input DNA of the given condition and digested with either HindIII (to detect unrepaired Cas9 DSB ends at c-Myc or ZFN DSB ends at Eb) or double digest with EcoRI and Ncol (to detect unrepaired $J_{\kappa}$ DSB ends). Southern probes used and additional methods are indicated (Supplement Methods and Table S4).

Data Deposition. Raw and processed sequencing data are available through GEO (GSE162453)

\section{Acknowledgements}

We thank members of the F.W.A and R.L.F. laboratories for stimulating discussions and feedback. We thank Barry Sleckman (University of Alabama) for the Lig4 ${ }^{-/} \mathrm{C}$ and Eb-ZFN expressing Lig4 ${ }^{-/} \mathrm{D}$ Abl lines. This work was supported by NIH grant AI020047 to F.W.A., an NIH Ruth L. Kirchstein National Research Service Award Fellowships CA189740 to V.K. and Al117920 to S.G.L., Cancer Research Institute Training Grant to C.B., and a Radiation Research Foundation Career Development Award to R.L.F. F.W.A is an Investigator of the Howard Hughes Medical Institute. R.L.F. is a V Scholar for the V Foundation for Cancer Research. 


\section{Literature Cited}

Adachi N, Ishino T, Ishii Y, Takeda S, Koyama H. 2001. DNA ligase IV-deficient cells are more resistant to ionizing radiation in the absence of Ku70: Implications for DNA double-strand break repair. Proc Natl Acad Sci U S A 98: 12109-12113.

Akbari M, Pena-Diaz J, Andersen S, Liabakk NB, Otterlei M, Krokan HE. 2009. Extracts of proliferating and non-proliferating human cells display different base excision pathways and repair fidelity. DNA Repair (Amst) 8: 834-843.

Alt FW, Zhang Y, Meng FL, Guo C, Schwer B. 2013. Mechanisms of programmed DNA lesions and genomic instability in the immune system. Cell 152: 417-429.

Audebert M, Salles B, Calsou P. 2004. Involvement of poly(ADP-ribose) polymerase-1 and XRCC1/DNA ligase III in an alternative route for DNA double-strand breaks rejoining. J Biol Chem 279: 55117-55126.

Ba Z, Lou J, Ye AY, Dai HQ, Dring EW, Lin SG, Jain S, Kyritsis N, Kieffer-Kwon KR, Casellas R et al. 2020. CTCF orchestrates long-range cohesin-driven V(D)J recombinational scanning.

Nature 586: 305-310.

Bakr A, Kocher S, Volquardsen J, Petersen C, Borgmann K, Dikomey E, Rothkamm K, Mansour WY. 2016. Impaired 53BP1/RIF1 DSB mediated end-protection stimulates CtIP-dependent end resection and switches the repair to PARP1-dependent end joining in G1. Oncotarget 7: 5767957693.

Boboila C, Jankovic M, Yan CT, Wang JH, Wesemann DR, Zhang T, Fazeli A, Feldman L, Nussenzweig A, Nussenzweig M et al. 2010a. Alternative end-joining catalyzes robust IgH locus deletions and translocations in the combined absence of ligase 4 and Ku70. Proc Natl Acad Sci U S A 107: 3034-3039.

Boboila C, Oksenych V, Gostissa M, Wang JH, Zha S, Zhang Y, Chai H, Lee CS, Jankovic M, Saez LM et al. 2012. Robust chromosomal DNA repair via alternative end-joining in the absence of X-ray repair cross-complementing protein 1 (XRCC1). Proc Natl Acad Sci U S A 109: 24732478.

Boboila C, Yan C, Wesemann DR, Jankovic M, Wang JH, Manis J, Nussenzweig A, Nussenzweig M, Alt FW. 2010b. Alternative end-joining catalyzes class switch recombination in the absence of both Ku70 and DNA ligase 4. J Exp Med 207: 417-427.

Bredemeyer AL, Sharma GG, Huang CY, Helmink BA, Walker LM, Khor KC, Nuskey B, Sullivan $\mathrm{KE}$, Pandita TK, Bassing $\mathrm{CH}$ et al. 2006. ATM stabilizes DNA double-strand-break complexes during $\mathrm{V}(\mathrm{D}) \mathrm{J}$ recombination. Nature 442: 466-470.

Ceccaldi R, Liu JC, Amunugama R, Hajdu I, Primack B, Petalcorin MI, O'Connor KW, Konstantinopoulos PA, Elledge SJ, Boulton SJ et al. 2015. Homologous-recombination-deficient tumours are dependent on Poltheta-mediated repair. Nature 518: 258-262.

Chang HHY, Pannunzio NR, Adachi N, Lieber MR. 2017. Non-homologous DNA end joining and alternative pathways to double-strand break repair. Nat Rev Mol Cell Biol 18: 495-506. 
Chen H, Zhang Y, Ye AY, Du Z, Xu M, Lee CS, Hwang JK, Kyritsis N, Ba Z, Neuberg D et al. 2020. BCR selection and affinity maturation in Peyer's patch germinal centres. Nature 582: 421425.

Chiarle R, Zhang Y, Frock RL, Lewis SM, Molinie B, Ho YJ, Myers DR, Choi VW, Compagno M, Malkin DJ et al. 2011. Genome-wide translocation sequencing reveals mechanisms of chromosome breaks and rearrangements in B cells. Cell 147: 107-119.

Corneo B, Wendland RL, Deriano L, Cui X, Klein IA, Wong SY, Arnal S, Holub AJ, Weller GR, Pancake BA et al. 2007. Rag mutations reveal robust alternative end joining. Nature 449: 483486.

Dai HQ, Hu H, Lou J, Ye AY, Ba Z, Zhang X, Zhang Y, Zhao L, Yoon HS, Chapdelaine-Williams AM et al. 2021. Loop extrusion mediates physiological lgh locus contraction for RAG scanning. Nature.

Deriano L, Chaumeil J, Coussens M, Multani A, Chou Y, Alekseyenko AV, Chang S, Skok JA, Roth DB. 2011. The RAG2 C terminus suppresses genomic instability and lymphomagenesis. Nature 471: 119-123.

Frank KM, Sekiguchi JM, Seidl KJ, Swat W, Rathbun GA, Cheng HL, Davidson L, Kangaloo L, Alt FW. 1998. Late embryonic lethality and impaired V(D)J recombination in mice lacking DNA ligase IV. Nature 396: 173-177.

Frank KM, Sharpless NE, Gao Y, Sekiguchi JM, Ferguson DO, Zhu C, Manis JP, Horner J, DePinho RA, Alt FW. 2000. DNA ligase IV deficiency in mice leads to defective neurogenesis and embryonic lethality via the p53 pathway. Mol Cell 5: 993-1002.

Frock RL, Hu J, Meyers RM, Ho YJ, Kii E, Alt FW. 2015. Genome-wide detection of DNA double-stranded breaks induced by engineered nucleases. Nat Biotechnol 33: 179-186.

Gao Y, Ferguson DO, Xie W, Manis JP, Sekiguchi J, Frank KM, Chaudhuri J, Horner J, DePinho RA, Alt FW. 2000. Interplay of p53 and DNA-repair protein XRCC4 in tumorigenesis, genomic stability and development. Nature 404: 897-900.

Gao Y, Sun Y, Frank KM, Dikkes P, Fujiwara Y, Seidl KJ, Sekiguchi JM, Rathbun GA, Swat W, Wang $\mathrm{J}$ et al. 1998. A critical role for DNA end-joining proteins in both lymphogenesis and neurogenesis. Cell 95: 891-902.

Gigi V, Lewis S, Shestova O, Mijuskovic M, Deriano L, Meng W, Luning Prak ET, Roth DB. 2014. RAG2 mutants alter DSB repair pathway choice in vivo and illuminate the nature of 'alternative NHEJ'. Nucleic Acids Res 42: 6352-6364.

Gouge J, Rosario S, Romain F, Poitevin F, Beguin P, Delarue M. 2015. Structural basis for a novel mechanism of DNA bridging and alignment in eukaryotic DSB DNA repair. EMBO J 34: 1126-1142.

Gu Y, Seidl KJ, Rathbun GA, Zhu C, Manis JP, van der Stoep N, Davidson L, Cheng HL, Sekiguchi JM, Frank K et al. 1997. Growth retardation and leaky SCID phenotype of Ku70deficient mice. Immunity 7: 653-665. 
Gu Y, Sekiguchi J, Gao Y, Dikkes P, Frank K, Ferguson D, Hasty P, Chun J, Alt FW. 2000. Defective embryonic neurogenesis in Ku-deficient but not DNA-dependent protein kinase catalytic subunit-deficient mice. Proc Natl Acad Sci U S A 97: 2668-2673.

Guirouilh-Barbat J, Rass E, Plo I, Bertrand P, Lopez BS. 2007. Defects in XRCC4 and KU80 differentially affect the joining of distal nonhomologous ends. Proc Natl Acad Sci U S A 104: 20902-20907.

Haber JE. 2008. Alternative endings. Proc Natl Acad Sci U S A 105: 405-406.

Hill L, Ebert A, Jaritz M, Wutz G, Nagasaka K, Tagoh H, Kostanova-Poliakova D, Schindler K, Sun $Q$, Bonelt $P$ et al. 2020. Wapl repression by Pax 5 promotes $V$ gene recombination by lgh loop extrusion. Nature 584: 142-147.

Hu J, Meyers RM, Dong J, Panchakshari RA, Alt FW, Frock RL. 2016. Detecting DNA doublestranded breaks in mammalian genomes by linear amplification-mediated high-throughput genome-wide translocation sequencing. Nat Protoc 11: 853-871.

Hu J, Zhang Y, Zhao L, Frock RL, Du Z, Meyers RM, Meng FL, Schatz DG, Alt FW. 2015. Chromosomal Loop Domains Direct the Recombination of Antigen Receptor Genes. Cell 163: 947-959.

Jain S, Ba Z, Zhang Y, Dai HQ, Alt FW. 2018. CTCF-Binding Elements Mediate Accessibility of RAG Substrates During Chromatin Scanning. Cell 174: 102-116 e114.

Kang YJ, Yan CT. 2018. Regulation of DNA repair in the absence of classical non-homologous end joining. DNA Repair (Amst) 68: 34-40.

Karanjawala ZE, Adachi N, Irvine RA, Oh EK, Shibata D, Schwarz K, Hsieh CL, Lieber MR. 2002. The embryonic lethality in DNA ligase IV-deficient mice is rescued by deletion of Ku: implications for unifying the heterogeneous phenotypes of NHEJ mutants. DNA Repair (Amst) 1: 1017-1026.

Kim MS, Lapkouski M, Yang W, Gellert M. 2015. Crystal structure of the V(D)J recombinase RAG1-RAG2. Nature 518: 507-511.

Komori T, Okada A, Stewart V, Alt FW. 1993. Lack of N regions in antigen receptor variable region genes of TdT-deficient lymphocytes. Science 261: 1171-1175.

Kumar V, Alt FW. 2016. NHEJ and Other Repair Factors in V(D)J Recombination. in Encyclopedia of Immunobiology, pp. 107-114. Elsevier.

Kumar V, Alt FW, Frock RL. 2016. PAXX and XLF DNA repair factors are functionally redundant in joining DNA breaks in a G1-arrested progenitor B-cell line. Proc Natl Acad Sci U S A 113:

10619-10624.

Lee BS, Gapud EJ, Zhang S, Dorsett Y, Bredemeyer A, George R, Callen E, Daniel JA, Osipovich O, Oltz EM et al. 2013. Functional intersection of ATM and DNA-dependent protein kinase catalytic subunit in coding end joining during $\mathrm{V}(\mathrm{D}) \mathrm{J}$ recombination. Mol Cell Biol 33: 3568-3579. 
Lee GS, Neiditch MB, Salus SS, Roth DB. 2004. RAG proteins shepherd double-strand breaks to a specific pathway, suppressing error-prone repair, but RAG nicking initiates homologous recombination. Cell 117: 171-184.

Lescale C, Abramowski V, Bedora-Faure M, Murigneux V, Vera G, Roth DB, Revy P, de Villartay JP, Deriano L. 2016. RAG2 and XLF/Cernunnos interplay reveals a novel role for the RAG complex in DNA repair. Nat Commun 7: 10529.

Lin SG, Ba Z, Alt FW, Zhang Y. 2018. RAG Chromatin Scanning During V(D)J Recombination and Chromatin Loop Extrusion are Related Processes. Adv Immunol 139: 93-135.

Lin SG, Ba Z, Du Z, Zhang Y, Hu J, Alt FW. 2016. Highly sensitive and unbiased approach for elucidating antibody repertoires. Proc Natl Acad Sci U S A 113: 7846-7851.

Mansour WY, Borgmann K, Petersen C, Dikomey E, Dahm-Daphi J. 2013. The absence of Ku but not defects in classical non-homologous end-joining is required to trigger PARP1-dependent end-joining. DNA Repair (Amst) 12: 1134-1142.

Mateos-Gomez PA, Gong F, Nair N, Miller KM, Lazzerini-Denchi E, Sfeir A. 2015. Mammalian polymerase theta promotes alternative NHEJ and suppresses recombination. Nature 518: 254257.

Nussenzweig A, Chen C, da Costa Soares V, Sanchez M, Sokol K, Nussenzweig MC, Li GC. 1996. Requirement for Ku80 in growth and immunoglobulin $V(D) J$ recombination. Nature 382 : 551-555.

Pryor JM, Waters CA, Aza A, Asagoshi K, Strom C, Mieczkowski PA, Blanco L, Ramsden DA. 2015. Essential role for polymerase specialization in cellular nonhomologous end joining. Proc Natl Acad Sci U S A 112: E4537-4545.

Ru H, Chambers MG, Fu TM, Tong AB, Liao M, Wu H. 2015. Molecular Mechanism of V(D)J Recombination from Synaptic RAG1-RAG2 Complex Structures. Cell 163: 1138-1152.

Schatz DG, Swanson PC. 2011. V(D)J recombination: mechanisms of initiation. Annu Rev Genet 45: 167-202.

Scully R, Panday A, Elango R, Willis NA. 2019. DNA double-strand break repair-pathway choice in somatic mammalian cells. Nat Rev Mol Cell Biol 20: 698-714.

Sfeir A, de Lange T. 2012. Removal of shelterin reveals the telomere end-protection problem. Science 336: 593-597.

Shamanna RA, Lu H, de Freitas JK, Tian J, Croteau DL, Bohr VA. 2016. WRN regulates pathway choice between classical and alternative non-homologous end joining. Nat Commun 7: 13785.

Smith J, Bibikova M, Whitby FG, Reddy AR, Chandrasegaran S, Carroll D. 2000. Requirements for double-strand cleavage by chimeric restriction enzymes with zinc finger DNA-recognition domains. Nucleic Acids Res 28: 3361-3369.

Soni A, Siemann M, Grabos M, Murmann T, Pantelias GE, lliakis G. 2014. Requirement for Parp-1 and DNA ligases 1 or 3 but not of Xrcc1 in chromosomal translocation formation by backup end joining. Nucleic Acids Res 42: 6380-6392. 
Stinson BM, Moreno AT, Walter JC, Loparo JJ. 2020. A Mechanism to Minimize Errors during Non-homologous End Joining. Mol Cell 77: 1080-1091 e1088.

Teng G, Schatz DG. 2015. Regulation and Evolution of the RAG Recombinase. Adv Immunol 128: 1-39.

Truong LN, Li Y, Shi LZ, Hwang PY, He J, Wang H, Razavian N, Berns MW, Wu X. 2013. Microhomology-mediated End Joining and Homologous Recombination share the initial end resection step to repair DNA double-strand breaks in mammalian cells. Proc Natl Acad Sci U S A 110: 7720-7725.

Wei PC, Chang AN, Kao J, Du Z, Meyers RM, Alt FW, Schwer B. 2016. Long Neural Genes Harbor Recurrent DNA Break Clusters in Neural Stem/Progenitor Cells. Cell 164: 644-655.

Yan CT, Boboila C, Souza EK, Franco S, Hickernell TR, Murphy M, Gumaste S, Geyer M, Zarrin AA, Manis JP et al. 2007. IgH class switching and translocations use a robust nonclassical end-joining pathway. Nature 449: 478-482.

Yu W, Lescale C, Babin L, Bedora-Faure M, Lenden-Hasse H, Baron L, Demangel C, Yelamos J, Brunet E, Deriano L. 2020. Repair of G1 induced DNA double-strand breaks in S-G2/M by alternative NHEJ. Nat Commun 11: 5239.

Zan H, Tat C, Qiu Z, Taylor JR, Guerrero JA, Shen T, Casali P. 2017. Rad52 competes with Ku70/Ku86 for binding to S-region DSB ends to modulate antibody class-switch DNA recombination. Nat Commun 8: 14244.

Zhang Y, Zhang X, Ba Z, Liang Z, Dring EW, Hu H, Lou J, Kyritsis N, Zurita J, Shamim MS et al. 2019. The fundamental role of chromatin loop extrusion in physiological $V(D) J$ recombination. Nature 573: 600-604.

Zhao L, Frock RL, Du Z, Hu J, Chen L, Krangel MS, Alt FW. 2016. Orientation-specific RAG activity in chromosomal loop domains contributes to Tcrd $\mathrm{V}(\mathrm{D}) \mathrm{J}$ recombination during $\mathrm{T}$ cell development. J Exp Med 213: 1921-1936.

Zhu C, Mills KD, Ferguson DO, Lee C, Manis J, Fleming J, Gao Y, Morton CC, Alt FW. 2002. Unrepaired DNA breaks in p53-deficient cells lead to oncogenic gene amplification subsequent to translocations. Cell 109: 811-821. 


\section{Figure legends.}

Figure 1. Disparate G1-arrested A-EJ outcomes of Cas9:c-Myc DSBs from specific core C-NHEJ deficiencies. A-B) Genome-wide prey-junctions from independently derived WT A and $\mathrm{B}, \mathrm{Lig} 4^{-/-} \mathrm{A} 1$ and $\mathrm{B} 1$ and $\mathrm{Ku} 70^{-/-} \mathrm{A} 1$ and $\mathrm{B} 1 \mathrm{Abl}$ lines are binned into $5 \mathrm{Mb}$ regions (black bars) and plotted on Circos plots displaying a 1/2/5 increment $\log _{10}$ scale (Frock et al., 2015). Bar height indicates junction frequency. Frequency ranges are colored by order of magnitude from very light $(<10)$ to dark orange $\left(>10^{5}\right)$. The light to dark red tone lines connecting the bait break to Ig loci represents translocation hotspots of greater significance. Circos plots are from pooled libraries after normalization, with total junctions indicated ( $n=3$ for each clone; see Table S1). C) Left: diagram of Cas9:c-Myc bait DSB locus (top) with Southern fragments $(\mathrm{H} 3=$ HindIII) detected by probe (middle; red dashed line) and HTGTS-JoinT-seq emphasizing Cut + Rejoined junctions (lower; red arow = bait primer). Right: Southern for Lig4 ${ }^{-/-}$A1 and B1 clones; cutting and G1-arrest are indicated. D-E) Bait break-site profiles for clone set $A(D)$ and $B(E)$. Junctions in both $(+)\left(\right.$ red) and (-)(blue) chromosome orientations plotted on $\log _{10}$ scale from pooled libraries indicated by total and average junction numbers ( $n=3$ for each clone, Mean $\pm S D$; One-way ANOVA with post-hoc Tukey's test, $P<0.05$, * $P<0.001$, ${ }^{* *}$, ns = not significant). F-G) Microhomology and insertion utilization of bait break-site junctions are plotted with indicated lengths ( $n=3$ for each clone, Mean \pm SD).

\section{Figure 2. Ku70 suppresses the rejoining and translocation of Cas9:C-Myc DSBs in Lig4-} deficient G1-arrested Abl cells. A) Genome-wide prey junctions from Cas9:c-Myc bait DSBs displayed as Circos plots (see Figure 1 legend; Table S1) for G1-arrested Lig4 ${ }^{-/} \mathrm{A} 1$, Lig4 ${ }^{-/} \mathrm{A} 1$ +Lig4, Lig4 ${ }^{-1-} \mathrm{Ku} 70^{-1-} \mathrm{A} 1-1$, and Lig4 ${ }^{-1-} \mathrm{Ku}^{-{ }^{--} \mathrm{A} 1-1}+\mathrm{Ku} 70 \mathrm{Abl}$ cells. B) Bait break-site junction profiles for Abl lines described in (A). Junctions are plotted similar to Fig. 1D ( $n=3$ for each clone; One-way ANOVA with post-hoc Tukey's test, $P<0.01,{ }^{* *}, P<0.001,{ }^{* * *}$; see Figure 1 legend). C) Microhomology and insertion usage of break-site junctions are plotted with indicated lengths ( $n=3$ for each clone, Mean $\pm S D$ ) for the Abl lines and conditions described in (A). 


\section{Figure 3. A-EJ of short 5' overhangs from ZFN cleavage are suppressed by Ku in Lig4-} deficient G1-arrested Abl cells. A) Genome-wide prey junctions from doxycycline-induced

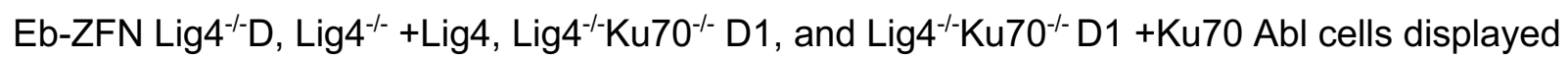
on Circos plots (see Figure 1 legend; Table S1). B) Induced Eb-ZFN bait break-site junction profiles from the G1-arrested Abl lines described in (A)( $n=3$ for each clone; One-way ANOVA with post-hoc Tukey's test, $P<0.0001,{ }^{* * * *}$; see Figure 1 legend). C) Microhomology and insertion usage of Eb-ZFN break-site junctions from the Abl lines described in (A) are plotted with indicated lengths ( $n=3$ for each clone, data represents Mean $\pm S D$ ).

\section{Figure 4. RAG DSBs are robustly joined to each other in the absence of the Ku DSB} sensor by a translocation-based A-EJ mechanism. A) HTGTS-V(D)J-seq examining joining patterns of prey $\bigvee_{\kappa}$ DSBs to the $\mathrm{J}_{\kappa} 1$ coding end comparing WT A, Ku70-/-A 1 , Lig4 $4^{-/} \mathrm{A} 1$ or Lig4 $4^{-/-}$ A1 + Lig4 Abl cells. Blue bars indicate junctions positioned in the (-) chromosomal orientation and red bars indicate junctions in the $(+)$ chromosomal orientation; depending on the relative orientation of the coding segments in $\lg \kappa$, junctions of either orientation will represent joins to either CEs or RSSs generated from RAG cleavage at a VкRSS. Joins falling within 200bp of a CE or RSS are plotted ( $n=3$ for each clone; One-way ANOVA to compare the ratios CE/RSS with post-hoc Tukey's test, $\mathrm{P}<0.001$, ${ }^{* * *}$; see Table S4). B) Zoom-in of selected $\mathrm{V}_{\kappa}$ gene segments from (A). C) HTGTS-V(D)J-seq using the same approach as (A) but comparing Lig4 ${ }^{-/-}$ $\mathrm{A} 1$, Lig4 ${ }^{-/-} \mathrm{Ku} 70^{-/-} \mathrm{A} 1-1$, and Lig4 ${ }^{-/-} \mathrm{Ku} 70^{-/-} \mathrm{A} 1-1+\mathrm{Ku} 70$ Abl cells. D) Zoom-in of selected $\mathrm{V} \kappa$ gene segments from (C). Microhomology and insertion usage in junctions joining from $\mathrm{J}_{\kappa} 1$ to $\mathrm{V}_{\kappa}$ segments are plotted with indicated lengths ( $n=3$ for each clone, data represents Mean $\pm S D$ ). 
Figure 1
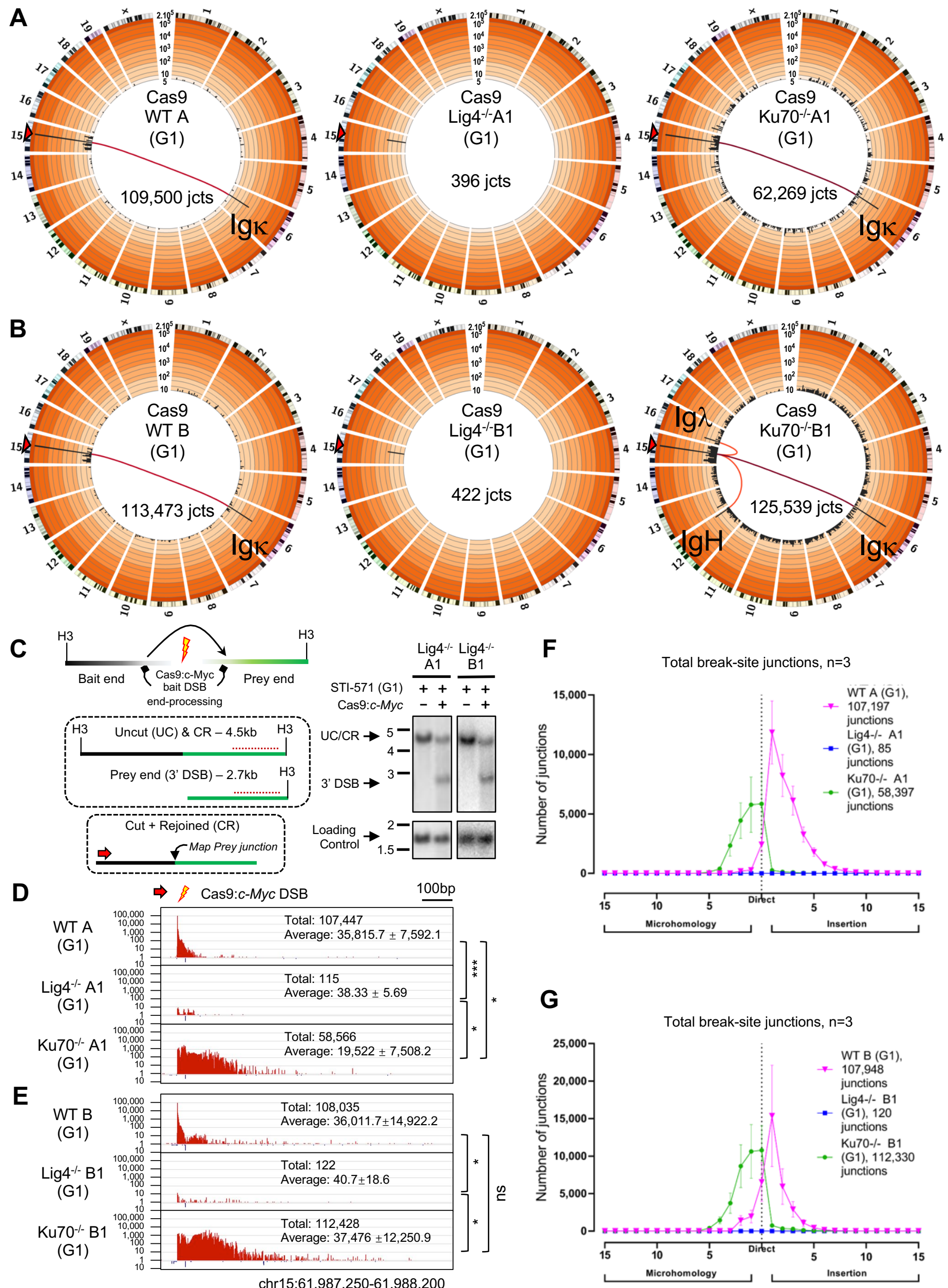

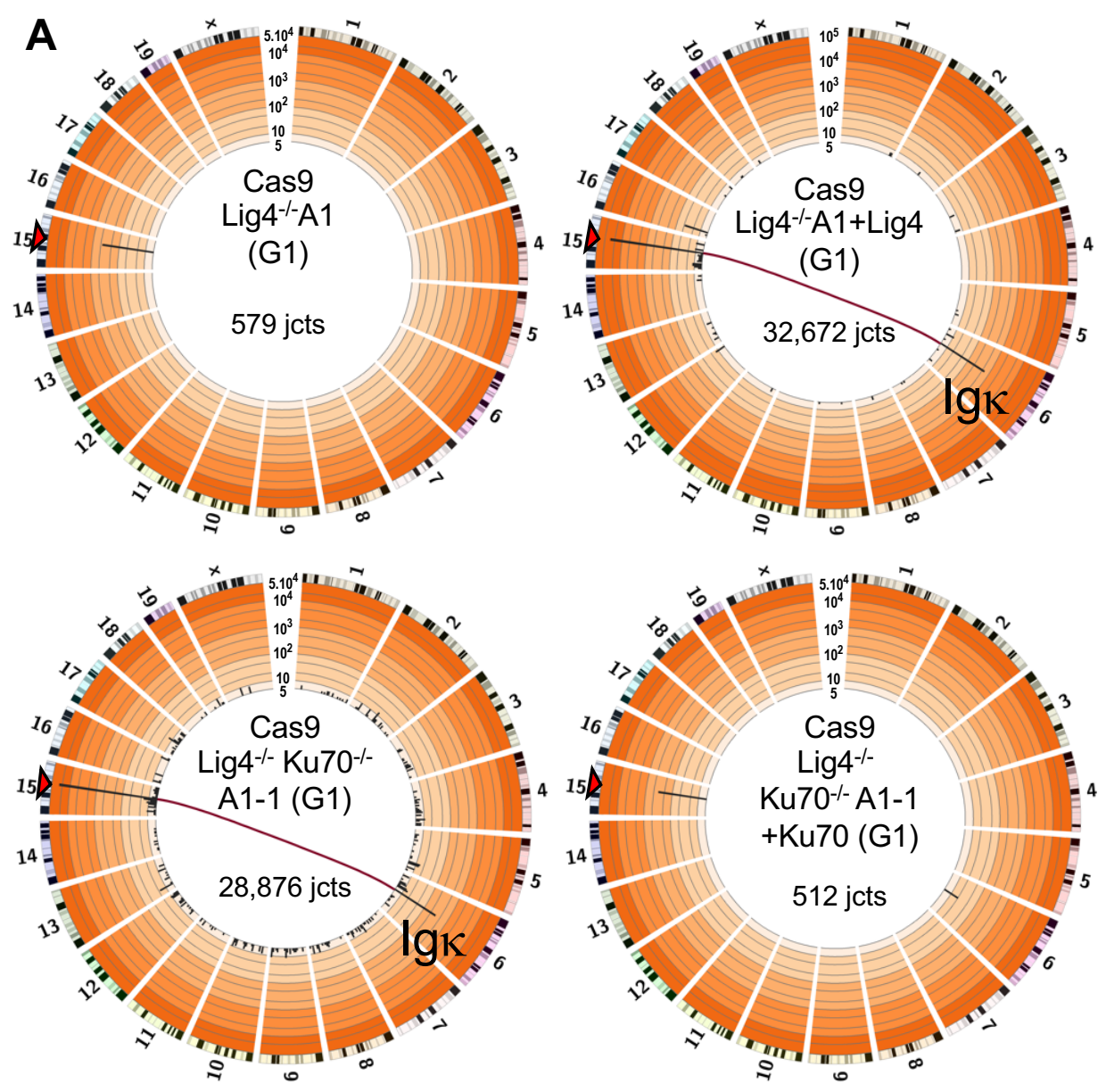

B

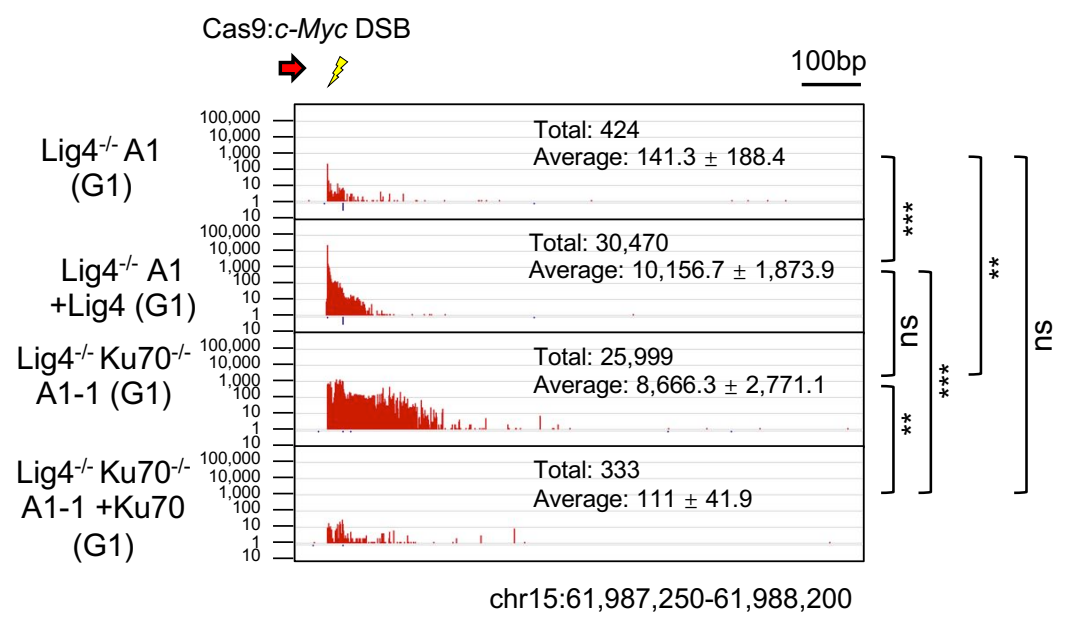

C

Total break-site junctions, $n=3$

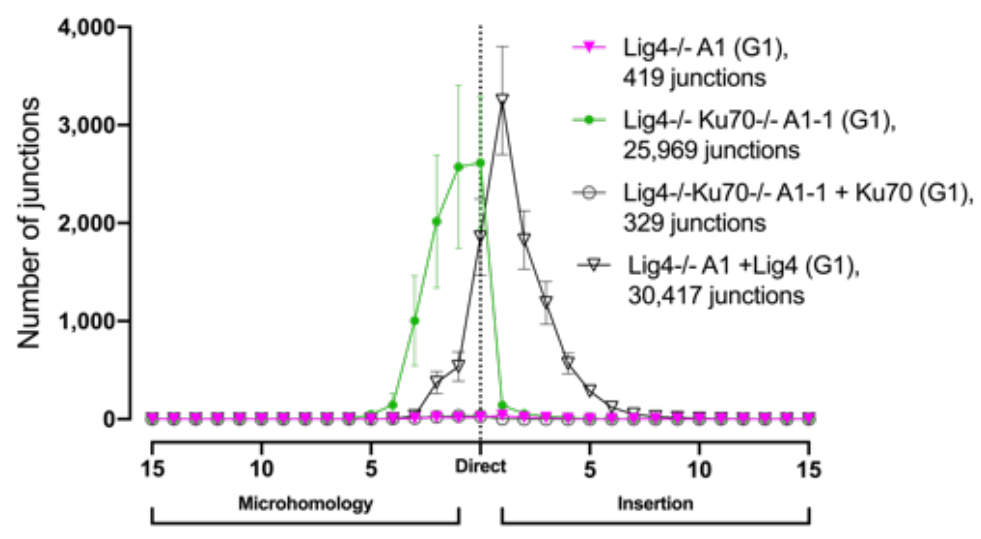


Figure 3
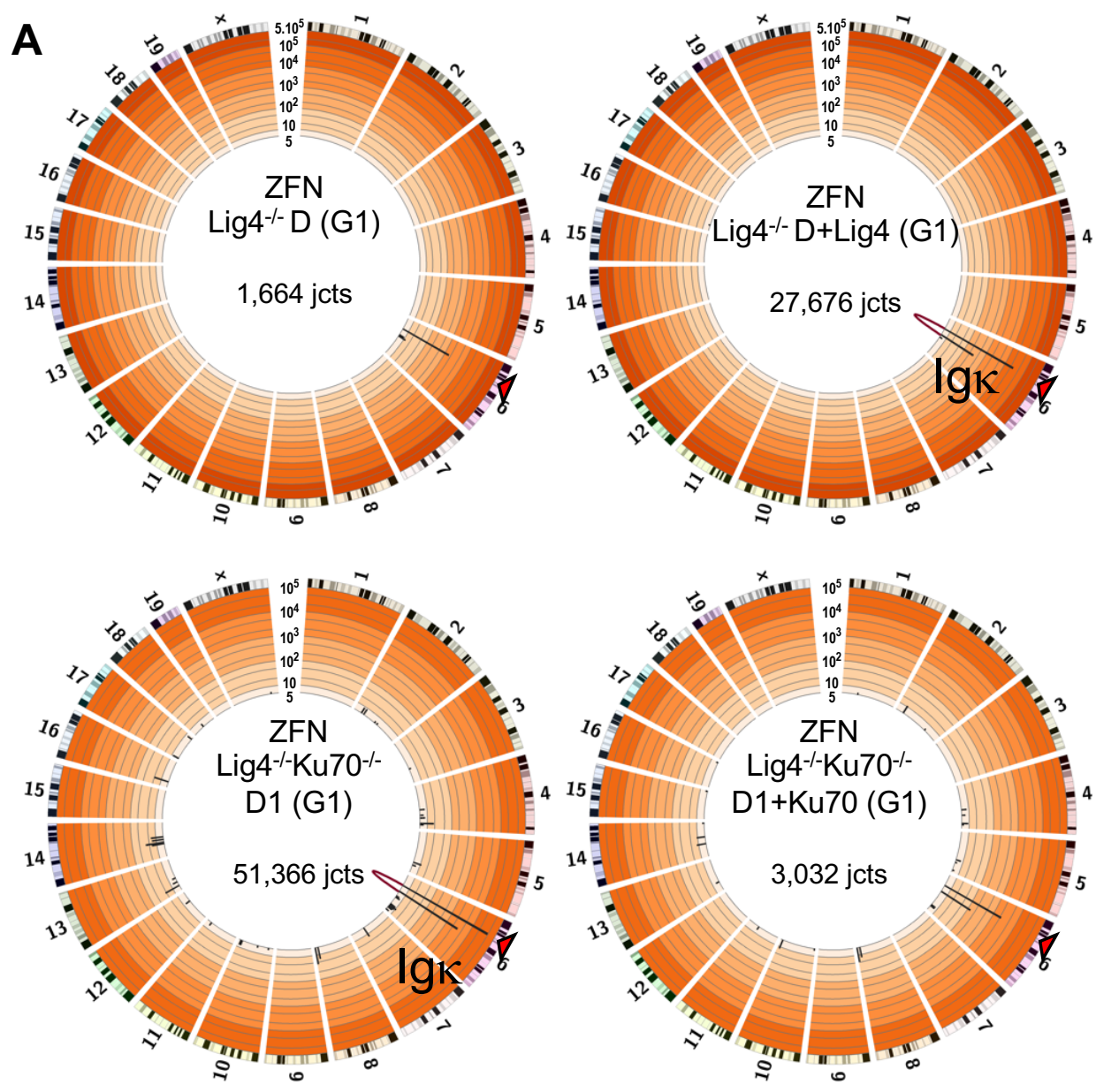

B

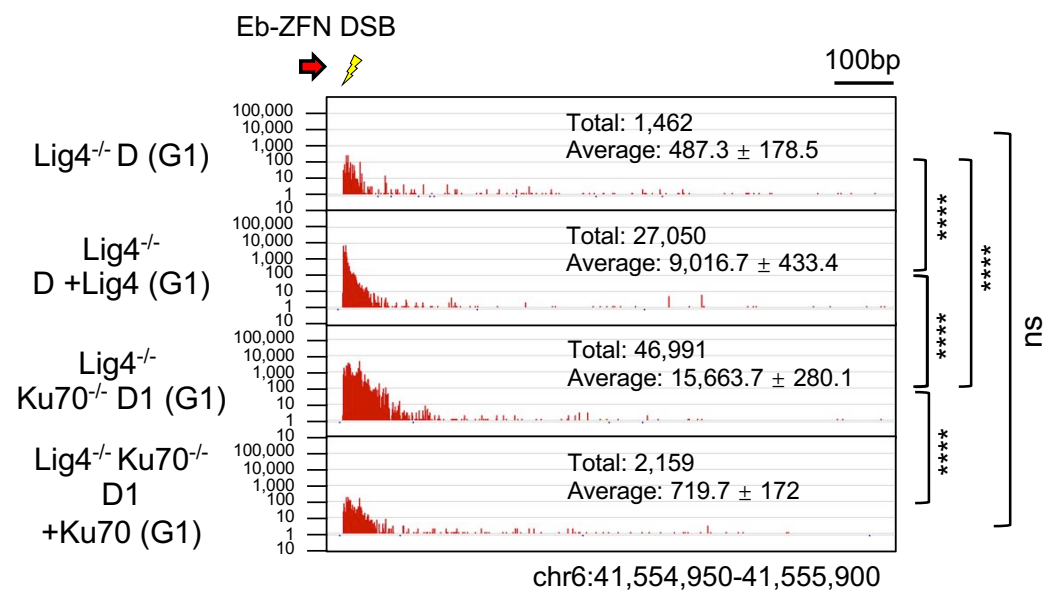

C

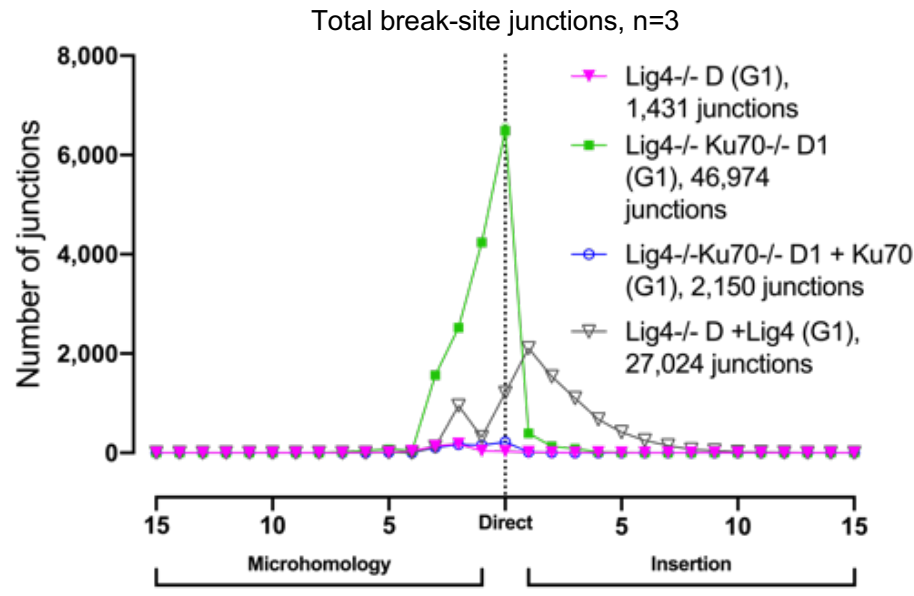


Figure 4

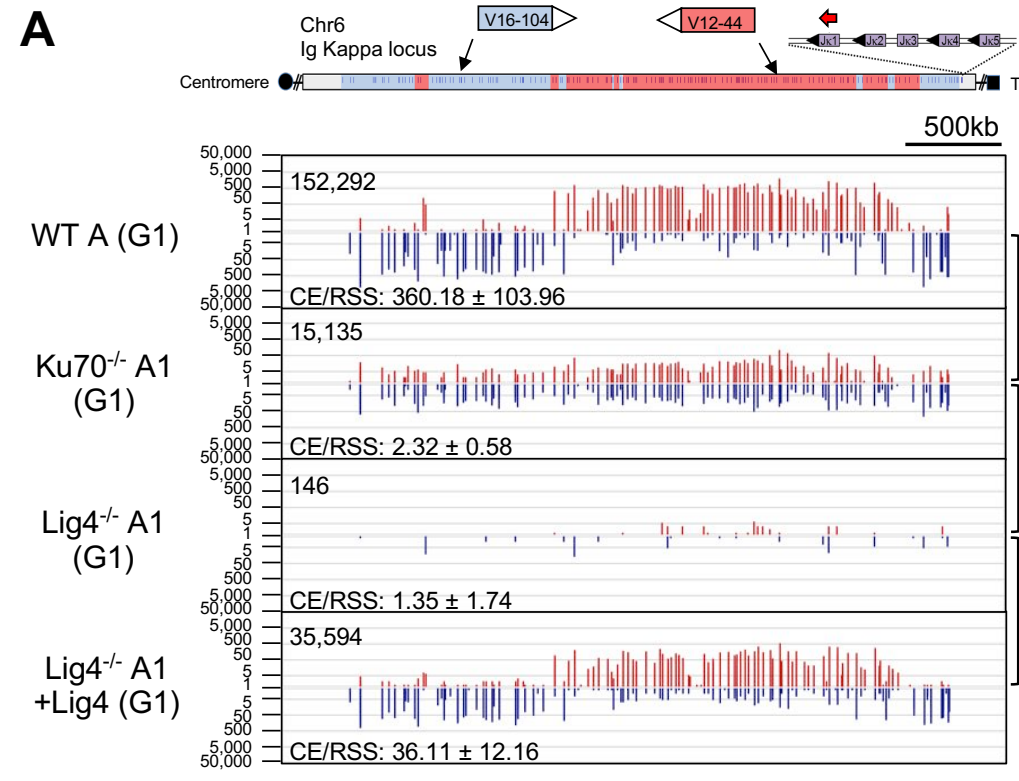

chr6:67,200,000-71,000,000

C

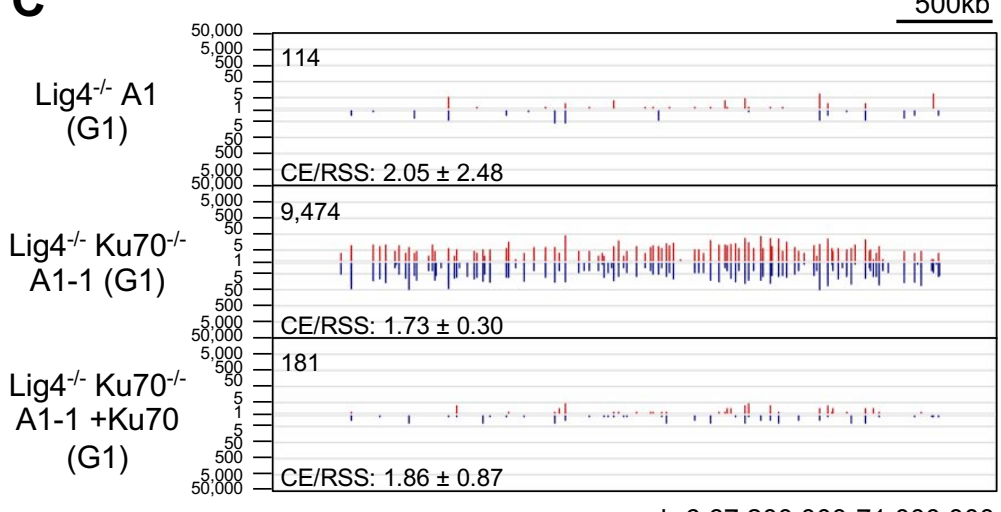

chr6:67,200,000-71,000,000
B
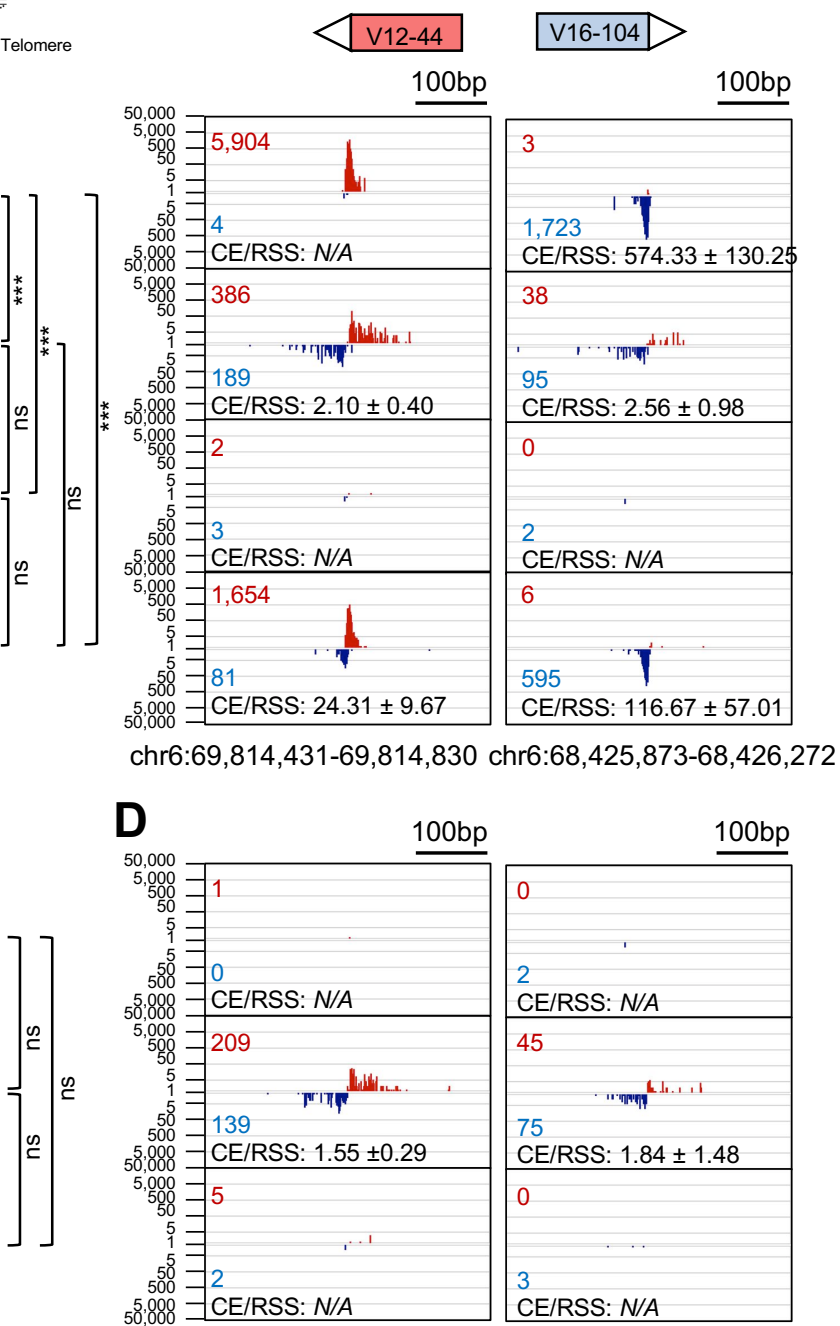

chr6:69,814,431-69,814,830 chr6:68,425,873-68,426,272
$\mathbf{E}$ Junctions to $V$ fragments, $n=3$

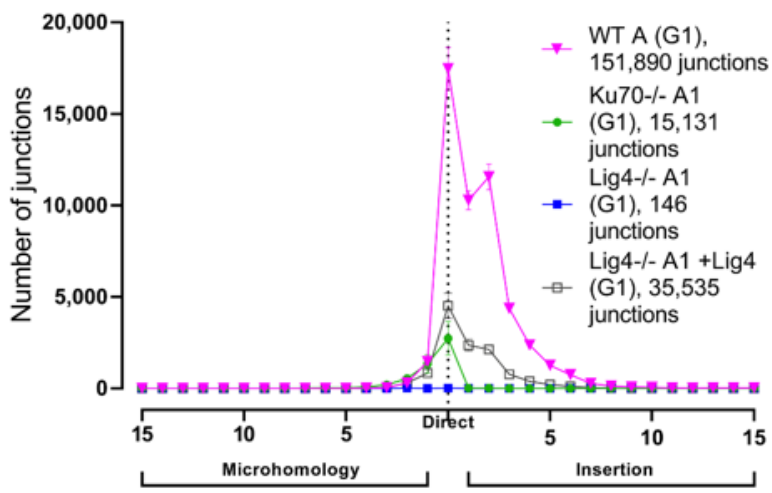

$\mathbf{F}$ Junctions to $V$ fragments, $n=3$

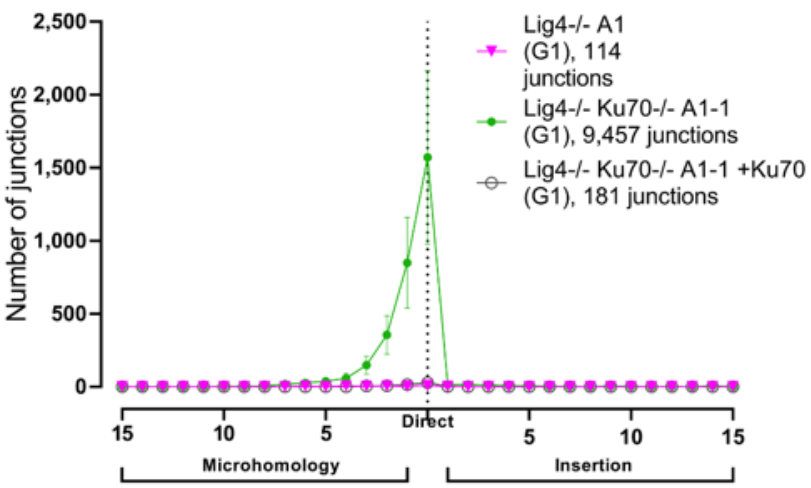

